\title{
The Researches on Construction Response and Excavation Method Optimization of Extra-large Cross-section Urban Subway Tunnel
}

\author{
Bo WU, ${ }^{\mathrm{a}, \mathrm{b}}$, Wei HUANG ${ }^{\mathrm{a}, \mathrm{b}}$, Yong Bo $\mathrm{ZHAO}^{\mathrm{c}}$ \\ ${ }^{a}$ College of Civil Engineering and Architecture, Guangxi University, Nanning, Guangxi 530004, China \\ bInstitute of Underground engineering, Guangxi University, Nanning, Guangxi 530004, China \\ ${ }^{\mathrm{c}}$ College of Civil Engeneering, FuJian University of Technology, Fuzhou, Fujian 350118, China
}

\begin{abstract}
In the extra-large cross-section urban subway underground station projects, the key problem is to choose the appropriate excavation method and grasp the mechanical behavior of the surrounding rock after excavation. The double side drift method is widely used in the urban subway underground station construction with extra-large cross-section in China. This paper presents the deformation characteristics of the extra-large cross-section tunnel of urban subway and a comparison with the numerical simulation results. In the city subway underground excavation of large section station, the mechanical behavior of surrounding rock change and its influence on the surrounding area mainly depend on the selection of construction methods. The convergent deformation of tunnel cavern, the subsidence of the surface and the force failure of the surrounding rock associated the construction approaches are demonstrated. This study provides a more in-depth demonstration of the way to optimize the excavation method of the extra-large cross-section tunnel to achieve the purpose of controlling the deformation of the surface and surrounding rock.
\end{abstract}

\section{Introduction}

With development and the urbanization of the city, the underground space development and the utilization of urban development have gradually become significant factors of cities' sustainable development $t^{[1]}$. Thus, when the excavation of extra-large cross-section tunnels or underground space is enforced, it could effectively solve the problem of urban sustainable development, but the inevitable environmental impacts and building operation bring challenges for engineers, that it inevitably disturbs the in situ stress field which causes ground movements leading to surface settlement, which may cause serious damage to adjacent structures ${ }^{[2]}$. It is essential to choose the proper excavation method for the construction of extra-large cross-section urban tunnel, because different excavation methods are of great significance for controlling the ground deformation and wall-rock convergence.

For the construction of urban subway tunnels in china, selecting a suitable design and construction method to complete the construction of the extra-large cross-section urban subway tunnel is the most critical factor to complete the whole project. It depends on the reasonable techniques and technologies adopted in the design and construction phase of the project, so as to achieve the goal of the highest construction efficiency and the lowest construction cost. These goal are strongly influenced by the excavation procedure.

In recent years, the research on the optimization of excavation methods of the underground stations is not concentrated. Tian L.F. ${ }^{[3]}$ concentrates some works on the support system optimization of double-side wall excavation method for subway station tunnel under complicated condition. Yu F.C. and Zhang D.L. ${ }^{[4]}$ study on excavation scheme optimization at the junction of pits and tunnels of subway station. Cheng T., Liu J.W. and Cao P. ${ }^{[5]}$ have focus on optimization analysis on construction scheme of large span metro station in hard rock stratum. These above researches are not focused on the common problems. Therefore, it is significant to find out the way to optimize the tunnel excavation method of extra-large cross-section station and the construction mechanics response of large section tunnel excavation.

\section{Project overview}

The Central Park East station of the metro line ten is located in the east of the Yubei District of the airport town in Chongqing, on the east side of the Tongmao Avenue. The Central Park East station adopts the $14 \mathrm{~m}$ island double decker station with a net width of $23.0 \mathrm{~m}$ and a net height of $19.0 \mathrm{~m}$. The maximum excavation span of the station is $24.54 \mathrm{~m}$, the excavation height is $21.52 \mathrm{~m}$, and the section area of excavation is $468.55 \mathrm{~m}^{2}$. The vertical wall circular arch section is adopted, and the composite lining is used in the structure.

*Corresponding author:813792833@qq.com 
The station surrounding rock is mainly mudstone, belongs to level IV and turns the soil thickness of 20.93 $\mathrm{m}$ to $30.16 \mathrm{~m}$. The station adopts the double side drift method construction. It sets a construction main channel into the station hall. In the construction main channel, it sets up an auxiliary channel to enter the station platform layer, with the length of $79.702 \mathrm{~m}$.
The Central Park East station adopts straight wall plus circular arch section, the excavation size of its standard section is $24.54 \mathrm{~m} * 21.52 \mathrm{~m}$, and the tunnel lining is composite lining. The design has 2 kinds of A1 and A2 type lining section $\left(468.55 \mathrm{~m}^{2}\right)$. The design parameters of the main section of the station are shown in table 1 and the design section is shown in fig. 1 .

\subsection{Design information of the Station}

Table1 Support parameter of main section

\begin{tabular}{|c|c|c|c|c|c|c|}
\hline \multirow{2}{*}{$\begin{array}{l}\text { Support } \\
\text { Type }\end{array}$} & \multirow{2}{*}{ application } & \multicolumn{4}{|c|}{ Supporting structure } & \multirow{2}{*}{$\begin{array}{l}\text { secondary } \\
\text { lining }\end{array}$} \\
\hline & & primary lining & spray concrete and steel mesh & anchor & grid arch & \\
\hline $\begin{array}{l}\text { IV level } \\
\text { A1 type } \\
\text { lining } \\
\text { section }\end{array}$ & $\begin{array}{l}\text { General } \\
\text { location }\end{array}$ & $\begin{array}{l}\varphi 42 \text { advanced small pipe, } \\
\mathrm{L}=4.5 \mathrm{~m} \text {,space in the } \\
\text { circumferential direction } \\
400 \mathrm{~mm} \text { grouting, array } \\
\text { pitch } 3.0 \mathrm{~m}\end{array}$ & $\begin{array}{l}\mathrm{C} 25 \text { concrete, thickness } 30 \mathrm{~cm} \\
\Phi 8 \text {-@ } 150 \times 150 \mathrm{mmbar}-\mathrm{mat} \\
\text { reinforcement, double-deck }\end{array}$ & $\begin{array}{c}\varphi 25 \text { grouted } \\
\text { rockbolt } \\
\mathrm{L}=4.0 \mathrm{~m}, \text { interval } \\
1.0 \mathrm{~m} \times 0.75 \mathrm{~m}, \text { in } \\
\text { passing quincunx }\end{array}$ & $\begin{array}{c}\text { I22b steel gantry } \\
0.75 \mathrm{~m} / \text { interval }\end{array}$ & $\begin{array}{l}\text { thickness } \\
85 \mathrm{~cm}, \mathrm{C} 40 \\
\text { concrete,P12 } \\
\text { reinforced } \\
\text { concrete }\end{array}$ \\
\hline $\begin{array}{l}\text { IV level } \\
\text { A2 type } \\
\text { lining } \\
\text { section }\end{array}$ & $\begin{array}{l}\text { Reinforced } \\
\text { intersections }\end{array}$ & $\begin{array}{c}\varphi 42 \text { advanced small pipe, } \\
\mathrm{L}=4.5 \mathrm{~m}, \text { space in the } \\
\text { circumferential direction } \\
400 \mathrm{~mm} \text { grouting, array } \\
\text { pitch } 2.0 \mathrm{~m}\end{array}$ & $\begin{array}{l}\mathrm{C} 25 \text { concrete, thickness } 30 \mathrm{~cm} \\
\Phi 8-@ 150 \times 150 \mathrm{mmbar}-\mathrm{mat} \\
\text { reinforcement, double-deck }\end{array}$ & $\begin{array}{c}\varphi 25 \text { grouted } \\
\text { rockbolt } \\
\mathrm{L}=4.0 \mathrm{~m} \text {, interval } \\
1.0 \mathrm{~m} \times 0.5 \mathrm{~m}, \text { in } \\
\text { passing quincunx }\end{array}$ & $\begin{array}{l}\text { I22b steel gantry } \\
0.5 \mathrm{~m} / \text { interval }\end{array}$ & $\begin{array}{l}\text { thickness } \\
85 \mathrm{~cm}, \mathrm{C} 40 \\
\text { concrete,P12 } \\
\text { reinforced } \\
\text { concrete }\end{array}$ \\
\hline
\end{tabular}

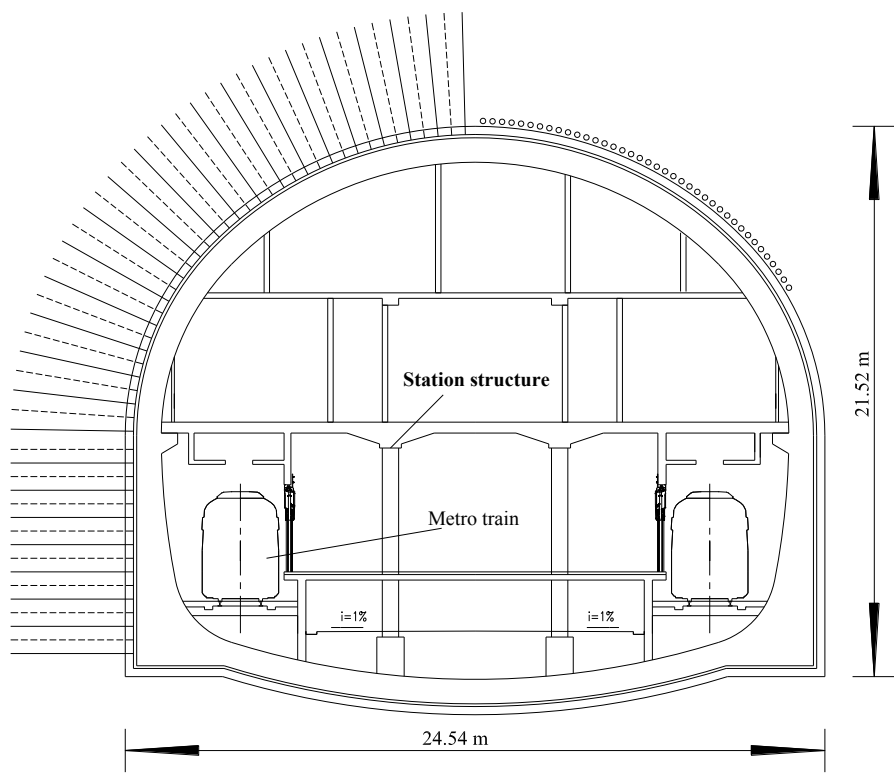

Fig.1 The section design of the Central park East station tunnel

excavation methods in urban area

\subsection{Geological and geotechnical investigation}

The original landform of Central Park east station is characterized by structural denudation and shallow mound topography. As a result of the urban area, the human engineering activities have greatly changed the topography and landscape. Along the ground, the elevation is $357 \sim 394 \mathrm{~m}$, and the relative elevation is about $37 \mathrm{~m}$. Along with the Tongmao Avenue, the whole of the vertical longitudinal slope is with the general slope angle of 2 4 degrees. Due to the transverse transformation to the original landform in the early stage of engineering construction, road or other construction scope of steep slope, is about 30 60 degrees.

\section{Conventional subway station}

\subsection{Finite element simulation}

Selecting a construction approach that is suitable for the extra-large cross-section tunnel of urban subway is significant. For this purpose, compared with the field monitoring, the numerical simulation has better flexibility to study the mechanical response of tunnel excavation in different environments ${ }^{[6]}$. A finite difference program named FLAC3D is applied to numerical analysis to evaluate the effect of the construction condition of the double side drift method.

When FLAC3D does with numerical simulation calculation, it must firstly specify the three basic conditions including the finite difference grids, the constitutive relation and material characteristics, the 
boundary and initial conditions. The grids are used to define the analysis model of geometry, and the constitutive relation and corresponding material properties of the model evaluate the mechanical response characteristics under external force, besides the boundary and initial conditions are used to define the initial state of the model. After processing these conditions, the initial state of the model could be solved by running the software of FLAC3D. Then, on the basis of the initial state, the loading of other simulation conditions and the tunnel excavation simulation are carried out. In turn, the response of the model is obtained after the simulation condition changing.

According to the geological survey report, the Mohr-Coulomb constitutive model is used in the calculation process, and the mechanical indexes of the surrounding rock are calculated as shown in table 2 .

Table2 Material parameter list

\begin{tabular}{ccccc}
\hline & $\begin{array}{c}\text { Elasticity modulus } \\
/ \mathrm{GPa}\end{array}$ & Poisson's ratio & Cohesive force /MPa & Friction Angle / \\
\hline Surrounding rock & 1.5 & 0.3 & 0.45 & 30 \\
Double layer steel arch & 36.6 & 0.2 & $/$ & $/$ \\
Secondary lining & 33.5 & 0.2 & $/$ & $/$ \\
Rock bolt & 210 & 0.3 & 0.69 & 30 \\
\hline
\end{tabular}

In the calculation process, the Mohr-coulomb model is used to simulate the tunnel surrounding rock, and the elastic model is used to simulate the initial supporting concrete and the shell unit is used to simulate the secondary lining. An equivalent method is used to simulate the rigid frame of the initial support, and the elastic modulus of the steel arch is converted into shotcrete

$$
E=E_{0}+\frac{S_{g} \times E_{g}}{S_{c}}
$$

In the formula: $E$-the elastic modulus of concrete after conversion; $E_{0}$ - the elastic modulus of the original concrete; $S_{g}$ - the sectional area of the steel arch; $E_{g}$ elastic modulus for steel; $S$ - Area of concrete.

Theoretical analysis ${ }^{[6]}$ shows that in the circular cavern excavation of the homogeneous elastic infinite domain, on account of the load release of the hole and the change of the stress and displacement, five times in the hole diameter outside is to $<1 \%$, and three times the hole diameter outside is about $<5 \%$. In the calculation process of this project, considering the continuity of the calculation process and the boundary truncation error generated by the impact, the size of the model is evaluated with the horizontal width of $160 \mathrm{~m}$, and the distance of vertical tunnel bottom is high hole 5 times. Besides, the length of the vertical direction is 100 meters, and the tunnel is 60 meters along the axial direction length. The calculation model for geometric dimensions is shown in fig.4.

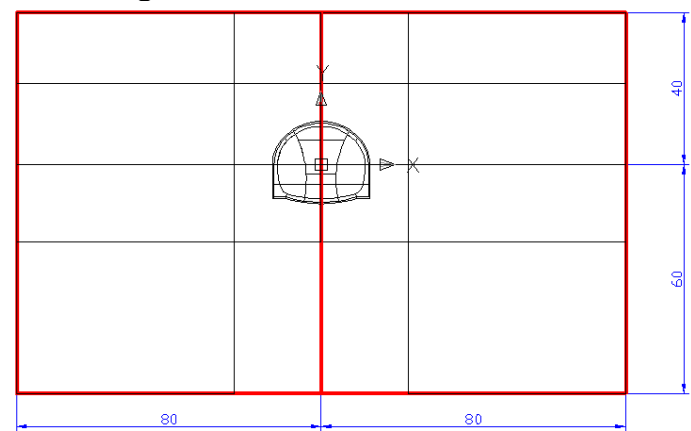

Fig.2 Geometric model of numerical calculation

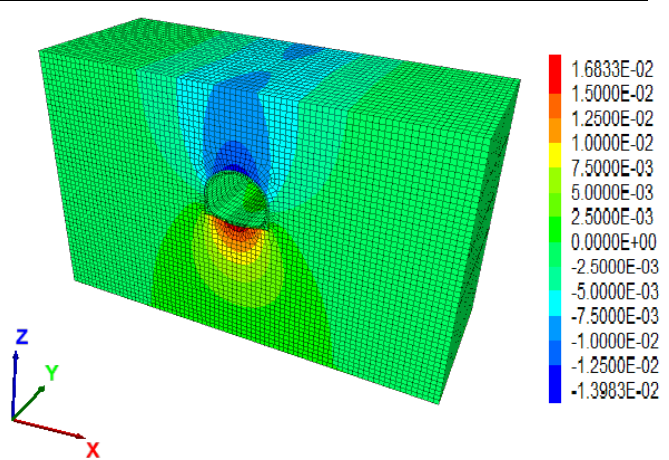

Fig.3 Distribution of overall vertical displacement

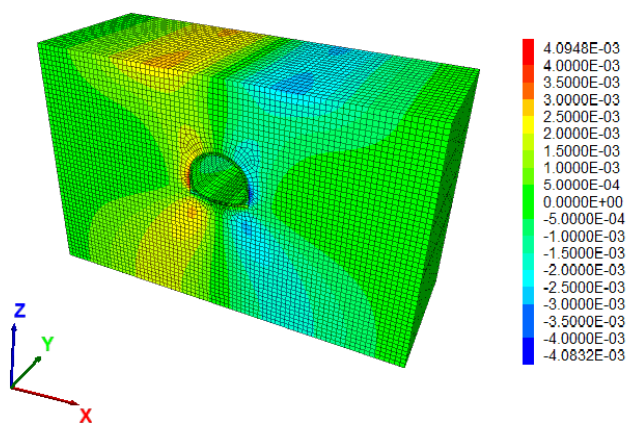

Fig.4 Distribution of overall horizontal displacement

As it could be seen from fig.4, the vertical deformation of the tunnel is concentrated in the arch and the inverted arch region, and the maximum deformation is $1.68 \mathrm{~cm}$. There is a clear sedimentation tank. As for the fig.5, the horizontal deformation of the tunnel is presented with a butterfly shape. The deformation of the tunnel is as long as the upper and lower sides of the early side wall of the tunnel, and the maximum deformation is equal to $4.08 \mathrm{~mm}$.

\subsection{Monitoring and analysis of the stability of surrounding rock}

The tunnel section of Central Park East station of the Chongqing metro line ten is super large $\left(468.55 \mathrm{~m}^{2}\right)$. In the excavation process, the stress distribution is so large that the tunnel surrounding rock deformation develops serious. And the tunnel is constructed by 9-steps excavation method, which is very easy to bring severe 
deformation of the top of tunnel in the middle stage of the excavation process and the ground subsidence which caused by tunnel excavation. Therefore, the activities and deformation of surrounding rock during the excavation of the tunnel would bring great difficulties and safety problems to the site construction. Thus, the monitoring of surrounding rock activities during tunnel excavation could predict the stability of surrounding rock in advance, and provide effective monitoring guidance for tunnel construction to reach the goals of safety, maintenance and protection. As shown in fig.2, a layout plan for surface subsidence monitoring points at the Central Park East station is shown.

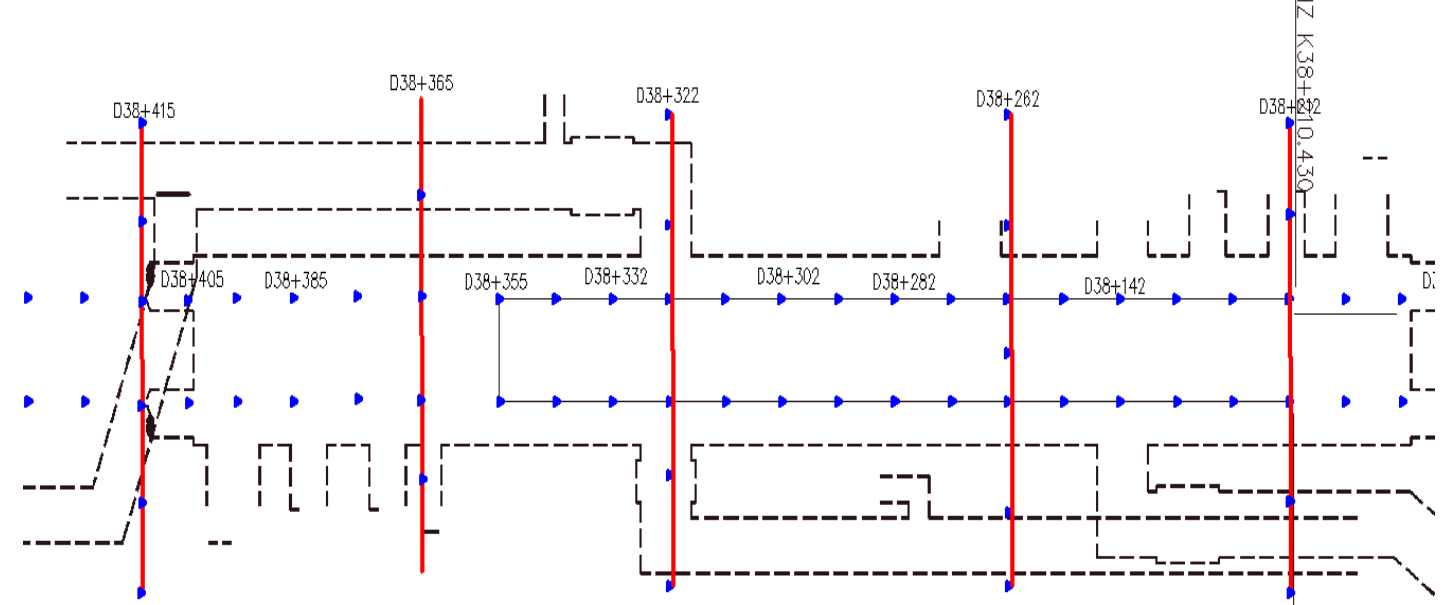

Fig.5 Surface settlement monitoring points of the station

The tunnel construction of Chongqing metro line ten is actually made from the middle to the two sides, and the actual test value of the surface of the tunnel is investigated in this phase. Thus, the results of numerical

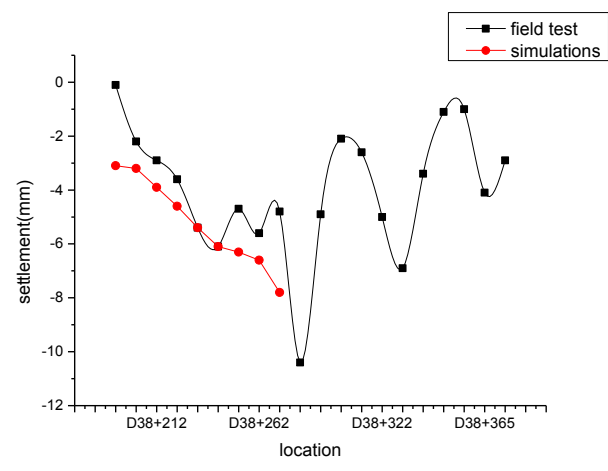

a) Subsidence along the left axis calculation could be compared and analyzed with the data of field monitoring.

(1) Deformation along the excavation direction

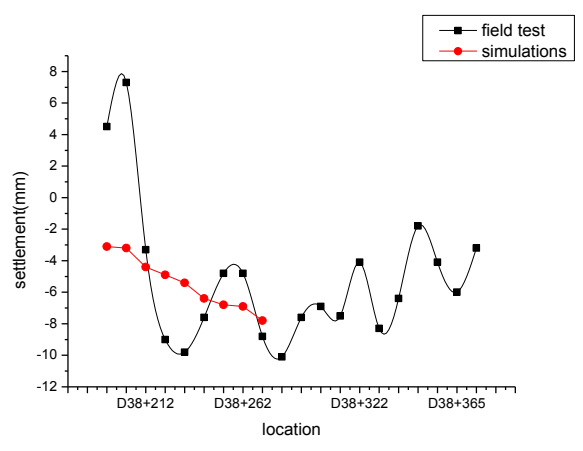

b) Subsidence along the right axis

Fig.6 Deformation along the excavation direction

From fig.6, under the job of comparing with the measured results and the results of numerical calculation, the actual excavation is through the channel from the middle part to finish the excavation construction. Therefore, it appears symmetry along the direction of excavation deformation law, which conforms to the actual situation. Moreover, the closer the excavation is to the working face, its deformation value is relatively small, and the core earth excavation is not related to the actual construction. After completion of the whole excavation, the surface deformation is relatively large because of strengthening support.

(2) Deformation along the cross-section of the tunnel

In the cases of the tunnel excavation along the section of the subsidence curve, it could effectively reflect the actual excavation unloading of surrounding rock and the effect of the selected tunnel section of $\mathrm{K} 38+212$ and $\mathrm{K} 38+262$ through tunnel cross section of the actual monitoring results. Thus, it could compare with the results of numerical calculation. 


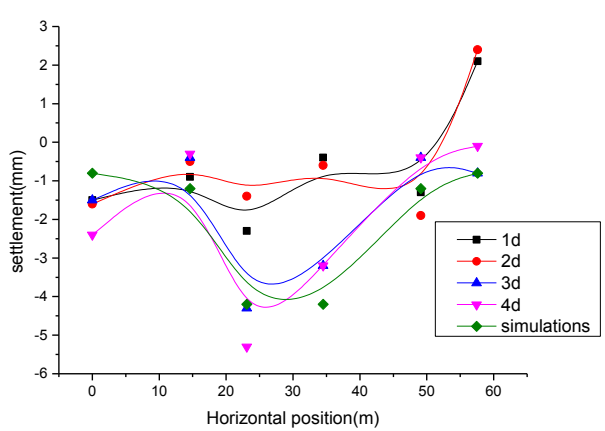

a) K38+212 sectional subsidence

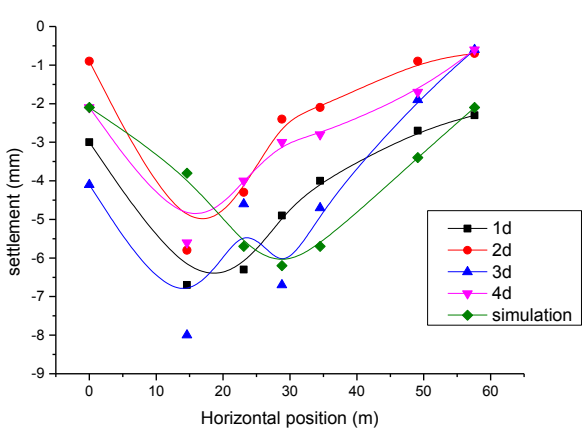

b) $K 38+262$ sectional subsidence

Fig.7 Deformation along the cross-section of the tunnel

In order to investigate the deformation of the tunnel excavation to the $\mathrm{D} 38+212$ section, the numerical calculation of the circular excavation steps and the excavation response of the tunnel are compared. The settlement deformation of the $\mathrm{K} 38+212$ section is relatively small due to the excavation of the K38+212 section, which is controlled at the level of $5 \mathrm{~mm}$. Differently, the section of $\mathrm{K} 38+262$ is at $8 \mathrm{~mm}$, which is relatively large. In the sections, there are some points in the middle because of the continuous operation of the excavation support. Moreover, the local regional support force is too large, which cause some points to bulge. In other part, due to environmental factors, some point measurement values are inconsistent with actual construction mechanical reactions.

Through the comparison analysis of the above numerical simulation and monitoring measurement, it could be concluded that the method of numerical calculation would effectively simulate the excavation calculation of large section tunnel. Therefore, different excavation schemes can be designed for numerical calculation, and then comparative analysis could be made to obtain the optimal excavation method.

\section{Optimization of tunnel excavation method}

\subsection{Large cross-section tunnel excavation method selection}

The super-large section tunnel could not be full face excavation directly. With the reason that if the section size is so large that the excavation unloading of soil grows too fast. Thus, the same is the bottom of the tunnel and the stress growth of the cavern surrounding due to the cavity support adversely ${ }^{[7]}$. Therefore, the large section of the tunnel needs to be divided into smaller parts. But for the way to divide and to determine the number of partitions and the size of the division and the choice of digging order is an urgent problem which needs to be solved.

With the perspective of meet the construction cost and construction efficiency etc., it is necessarily to consider the existing construction experience and to analyze and summary the research achievements of both domestic and foreign experts and scholars to conduct the tunnel construction. The preferred method of tunnel construction is to excavate the whole section with steps. Thus, the second choose is the circular excavation core method according to actual condition. When the poor geological conditions and large cross section selection is in the next door or cross the wall, and the tunnel cross section larger needs to be divided into multiple small cavern respectively, so the double side drift method construction is the most suitable choose. Once the worse geological condition and the bigger section is, the more difficulty of the tunnel excavation is, and the construction would be more complicated. From the angle of stress deformation of construction safety, tunnel surrounding rock and supporting structure, the selection method of selecting excavation method should be matched in reverse.

It is found that on account of the construction of high efficiency, as a result, its construction section division and excavation supporting measures are relatively simple. But to guarantee the condition of rather smaller structure safety and stress, with the condition of the large cross section, it needs to divide into various complex construction parts. Therefore the demands of the way to balance the contradiction and then to choose the appropriate method are required including the problems to be settled urgently in determining the construction methods and its main performance excavation size, construction sequence, and so on.

So, for the ways to choose appropriate and optimization of large cross section tunnel construction method, the size of the excavation steps and excavation sequence, this paper would gradually deepening the study from the aspects of plane partition optimization.

\subsection{Principle of dynamic planning of tunnel construction}

In tunnel construction, owing to the reason that there are a few construction process of tunnel construction, and the construction process have successively, the whole process of tunnel construction could be divided into a number of interrelated construction stage namely the construction step. In every stage, it needs to make policy which is to make corresponding decision and to enter the next step. Moreover, it includes deciding what measures to take and how to carry out the excavation support, so that the whole process could achieve the best excavation supporting and economy effect. 
Therefore, the decision selection of each stage construction step could not be determined arbitrarily ${ }^{[8]}$. It depends on the current construction state, and it would affect the excavation support status after the construction state. The stage when the decisions have determined after choosing the next step of construction measures for the construction is composed of a tunnel construction decision-making sequence. As a result, the process of the whole tunnel construction excavation supports implementation process route. Such as the problem of a tunnel excavation construction process associated with chain structure before and after a multi-stage process is called a multi-stage decision process in tunnel construction. This kind of problem is called the multi-stage decision optimization problem in tunnel construction. Such kinds of problems could be solved by dynamic programming theory.

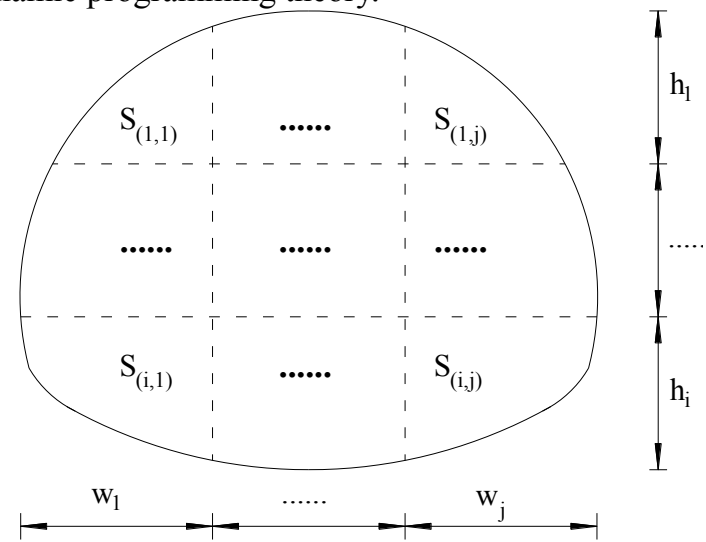

Fig.8 Plane sub-area optimization model

The theory of tunnel excavation optimization is based on dynamic programming theory. The simplified model of excavation optimization of tunnel section is shown in Fig.8. Optimization analysis process is below.

(1) According to the plane partition optimization model $f_{x y}=f[(i, h),(j, w)]$, then it needs to determine the optimal parameters $i, j 、 h 、 w$.Among them, $f_{\mathrm{xy}}{ }^{-}$ the theoretical model of the transverse partition excavation scheme, $i$ - horizontal layering, $h$ - the collection of steps including $h_{1} \ldots . h_{i}, \sum h_{i}=H$ - the height of the tunnel section, $j$ - transverse block

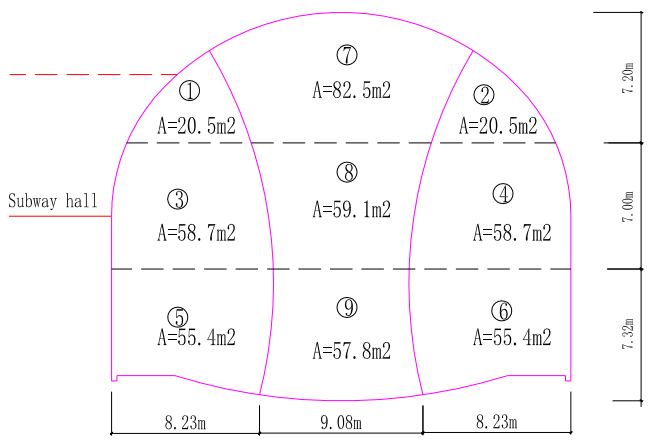

Design 9 blocks

Fig.9 Optimization proposal section

The optimized scheme is shown in fig.9, and the tunnel excavation method of the double side drift method number, $w$ - the collection of steps including $w_{1} \ldots w_{j}, \sum w_{j}=W$ - the width of the tunnel section.

(2) In view of the optimization parameters of the plane partition $i, j, h, w$, it could number the flat partition. Therefore, the dynamic model of tunnel excavation method is constructed.

(3) Through a series of calculations and analyses of comprehensive analysis of various in the tunnel excavation scheme of the optimal evaluation standards, and to determine the parameters of evaluation criteria, namely, building dynamic programming model of objective function, and to solve the optimal solution of the model with the iterative calculation method, the optimal method of excavation would be found.

(4) The optimal scheme is further analyzed and calculated, and the construction support measures and corresponding parameters are determined.

\subsection{Optimization proposal analysis}

Due to the construction parameters, the optimization of the construction scheme has the effect of modifying the single parameter. As shown in fig.9, the design of the design of the 9-step construction methods is found in the actual production, which is the construction method of the double side drift method construction. The construction channel through the $\mathrm{S}(1,1)$ and $\mathrm{S}(2,1)$ block would be divided into two parts. After the excavation of $S(1,1)$ block, the excavation of the $S(2,1)$ block is carried out, it is difficult to avoid the processing of the construction channel, because it is in the middle of the upper and lower layers, which is the temporary inverted arch used for layering during construction. Therefore, it is necessary to optimize the excavation method of the double side wall of the tunnel construction. For the reasons of the improvement of the construction environment, the solution of the lateral wall and the application of the temporary inverted arch, in the optimization scheme, the existing excavation support parameters are maintained, so only the size and order of excavation are optimized and analyzed.

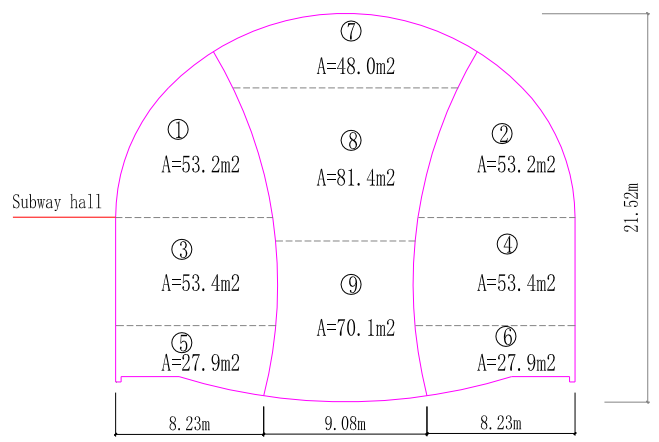

Optimize 9 blocks construction would continue to be used, namely $i=j=3$.

Only the parameter $h$ collection is optimized. 
Considering the actual conditions of construction, the lower part of $S(1,1)$ is adjusted to the station floor, so that it is easy for construction vehicles to enter through construction channels and tunnel sections through the station floor. Therefore, it could optimize the design of follow-up construction.

At the same time, the $S(2,1)$ region is adjusted downward, and the top block $\mathrm{S}(3,1)$ of the inverted arch is reduced. Thus, the operations of reducing the $S(2,1)$ area which takes artificial excavation and reducing the disturbance of the large section tunnel has significant to the surrounding rock, especially for the control of the deformation of the arch. The $\mathrm{S}(2,2)$ zone and the $\mathrm{S}(3,2)$ area are correspondingly enlarged, and the area of the core soil is increased to facilitate the stability of the tunnel during the construction period. At the same time, the most of the core soil is reserved in the middle so as to facilitate the subsequent construction and mechanical excavation.

Table3 Parameter comparison before and after optimization

\begin{tabular}{llllllllll}
\hline Parameter & $h_{(1,1)}$ & $h_{(1,2)}$ & $h_{(1,3)}$ & $h_{(2,1)}$ & $h_{(2,2)}$ & $h_{(2,3)}$ & $h_{(3,1)}$ & $h_{(3,2)}$ & $h_{(3,3)}$ \\
\hline Before (m) & 5.08 & 7.20 & 5.08 & 7.00 & 7.00 & 7.00 & 6.45 & 7.32 & 6.45 \\
After (m) & 9.20 & 4.12 & 9.20 & 5.95 & 8.50 & 5.95 & 3.38 & 8.95 & 3.38 \\
\hline
\end{tabular}

Due to changes in each partition, the actual excavation area of each partition is changed. Some of the excavation area is increased, correspondingly some of the excavation area is decreased. So the actual excavation unloading process changes, whether the design sequence can continue to be used, there needs to further optimize the demonstration.

Therefore, for the problem of excavating large section into 9 areas for multi-stage and multiple decision making, dynamic programming model and analytic hierarchy

process model could be used together to analysis the optimize problem.

\subsection{Optimization result analysis}

Through the above optimization analysis, the main results are shown in table 2 . The analysis of the first three of the comprehensive evaluation index is carried out.

Table4 Excavation optimization results

\begin{tabular}{cccc}
\hline Serial number & Excavation sequence & Evaluation index & Remarks \\
\hline 1 & $\mathrm{~S}(1,1)-\mathrm{S}(1,3)-\mathrm{S}(2,1)-\mathrm{S}(2,3)-\mathrm{S}(3,1)-\mathrm{S}(3,3)-\mathrm{S}(1,2)-\mathrm{S}(2,2)-\mathrm{S}(3,2)$ & 3.532 & optimal \\
2 & $\mathrm{~S}(1,1)-\mathrm{S}(1,3)-\mathrm{S}(2,1)-\mathrm{S}(2,3)-\mathrm{S}(1,2)-\mathrm{S}(3,1)-\mathrm{S}(3,3)-\mathrm{S}(2,2)-\mathrm{S}(3,2)$ & 3.465 & Suboptimal \\
3 & $\mathrm{~S}(1,1)-\mathrm{S}(2,1)-\mathrm{S}(3,1)-\mathrm{S}(1,3)-\mathrm{S}(2,3)-\mathrm{S}(3,3)-\mathrm{S}(1,2)-\mathrm{S}(2,2)-\mathrm{S}(3,2)$ & 3.412 & Suboptimal \\
\hline
\end{tabular}

Table 2 lists the results of the first three of the comprehensive evaluation index, and the first row is the optimal excavation sequence. In the tunnel excavation section is divided into left and right three transverse block, upper and lower three layers, thus the construction is conducted in accordance with the cross excavation, finally the central core soil excavation would be finished.

\section{Discussion and conclusion}

Thesis research takes extra-large cross-section urban subway tunnel as the background, furthermore comprehensive methods are adopted including the technology research, theoretical analysis, numerical simulation, field test and other means. The optimization of super-large section tunnel excavation method, super-large section tunnel construction process simulation, super-large section tunnel surrounding rock stability monitoring measurement, etc. are carried on the thorough research systematically.

The main research work and research conclusion sum up as follows:

1. The construction of the double side drift method is used to measure the tunnel of the Central Park East station of Chongqing metro line ten. The monitoring results are compared with the numerical simulation results. The results show that the deformation law is approximately the same and the deformation quantity is at the same level by comparing the measured values and the numerical results. Therefore, the method of numerical calculation could be used to optimize the excavation method.

2. In this paper, the global optimization theory is analyzed, and the multi-stage optimization process of tunnel engineering is given priority to match the dynamic programming theory to optimize the selection of multiple schemes. In particular, the multi-objective planning theory is analyzed and the analytic hierarchy analysis model is used to evaluate and make the decision of tunnel excavation. The application range of optimization theory is studied, and the optimization of tunnel excavation method based on dynamic programming theory is finally adopted.

3 . through the analysis of common construction method of the double side drift method, A unified planar partition model of $f_{x y}=f[(i, h),(j, w)]$ is constructed, which could explain the problem of the tunnel excavation plane optimization through the four parameters such as $i, j \quad h$ and $w$.

4. By means of the analysis of the Central Park East 
station actual optimization problem of the Chongqing metro line ten, the construction parameters are optimized, by using the theory of dynamic programming. Finally, the optimal excavation scheme of comprehensive evaluation index is chosen.

This article mainly from the space effect of super-large section tunnel excavation method optimization and construction mechanics of material are discussed in this paper. Moreover it is necessary to do some further research concerning the effect of time and space, and to provide better guidance for similar engineering design and construction reference.

\section{Acknowledgement}

The authors acknowledge the financial support of the National Science of China (51478118, 51678164). The authors would like to express the appreciation and thanks to the managers and China Tiesiju Civil Engineering Group Co., LTD.

\section{Reference}

1. Sharifzadeha M, Kolivand F, Ghorbani M, Yasrobi S.Design of sequential excavation method for large span urban tunnels in soft ground-Niayesh tunnel[J]. Tunnel and Underground Space Technology, 2013, 35:178-188

2. P.F Li, Y Zhao. Performance of a multi-face tunnel excavated in loess ground based on field monitoring and numerical modeling [J]. Arabian Journal of Geosciences, 2016, 9 (14):640

3. TIAN Li-Feng. Support System Optimization of Double-side Wall Excavation Method for Subway Station Tunnel under Complicated Condition [J]. Railway station design, 2016, 60(7): 130-133

4. Yu F.C, Zhang D.L, Mu W.G, Wang J.C. Study on excavation scheme optimization at the junction of pits and tunnels of subway station [J].Journal of Beijing Jiao tong University, 2015, 39(6):69-73

5. Cheng T, Liu JW, Cao P. The Optimization Analysis on Construction Scheme of Large Span Metro Station in Hard Rock Stratum [J]. Chinese Journal of Underground Space and Engineering, 2014, 10(3):635-640

6. $\mathrm{Wu} Z \mathrm{ZJ}$, Fan LF. The numerical manifold method for elastic wave propagation in rock with time-dependent absorbing boundary conditions [J]. Engineering Analysis with Boundary Elements, 2014, 46:41-50

7. Peter J, Sellner, Schubert W. Prediction of Displacement in Tunnel [D].Graz University of Technoloy.2000.

8. Wu B, GAO B. Optimization Analysis of Excavation Sequence of Tunnel Groups between Metro Stations [J]. China railway science, 2003, 24(5):23-28 